\title{
Analysis of dynamics of mitral Starr-Edwards valve prosthesis using reflected ultrasound
}

\author{
D. C. Siggers, ${ }^{1}$ Sivaporn A. Srivongse, and Dennis Deuchar \\ From the Cardiac Department, Guy's Hospital, London S.E.I
}

The speed of closure of the mitral valve during diastole, as recorded by ultrasonocardiography, is reduced in patients with mitral stenosis. A pattern of movement similar to that of severe mitral stenosis is seen in recordings from patients with normally functioning mitral Starr-Edwards prostheses. Simultaneous ultrasound recordings of ball and cage movements show that the prosthetic valve remains fully open during diastole, and that the movement recorded during this period is due to the cage only. It is probable that in severe mitral stenosis also, the valve remains fully open during diastole and, by analogy, the movement recorded is due to the mitral ring only. A possible explanation for this similarity is that the vortex mechanism which is thought to occur in association with normal mitral valve function is absent in both severe mitral stenosis and in the normally functioning mitral Starr-Edwards prosthesis. The opening speed of the mitral Starr-Edwards prostheses against gravity is slower than the speed of opening in the direction of gravity. In the normally functioning mitral Starr-Edwards prosthesis, a 'puff' of regurgitation occurs through the valve lumen at the onset of each systole.

The use of reflected ultrasound for detecting the movement of intracardiac structure was first reported in 1954 by Edler and Hertz; they showed that the movement of the anterior cusp of the mitral valve could be recorded by this method. Edler and Gustafson (1957) showed that the pattern of movement was altered in mitral stenosis, and their findings were later confirmed and extended (Edler et al., 1961; Joyner, Reid, and Bond, 1963; Effert, I963; Segal, Likoff, and Kingsley, 1966; Wharton 1969). The pattern of movement of the anterior mitral cusp in mitral incompetence has also been shown (Segal, Likoff, and Kingsley, 1967).

The pattern of movement of the normal mitral valve as recorded by ultrasound is shown diagrammatically in Fig. I, with the nomenclature proposed by Edler (I96I). In patients with mitral stenosis the E-F slope falls more slowly than in the normal subject.

The movements of the Starr-Edwards prosthetic valve were first described in 1967 by Winters, Gimenez, and Soloff; initially these movements were determined by detailed frame-by-frame analysis of cineangiocardiographic films. Movements of both the ball and the frame were analysed. The ball movements Received 5 October 1970.

1 Present address: 28 Woodville Road, New Barnet, Herts. as determined in this way agreed with the pattern shown by the ultrasound technique and resembled the pattern of movement of the anterior cusp of the mitral valve in mitral stenosis, though cardiac catheterization showed no significant gradient across the valve. Two possible explanations for this resemblance were suggested by these authors: that the flow characteristics through the prosthetic valve might be responsible or that it might be due to inertia of the prosthetic ball. The latter explanation was not favoured because changes in the timing of the opening and closing of the valves would be expected if this was the explanation, and these did not appear to occur in their recordings. The present study attempts to elucidate the mechanism of this 'stenotic' pattern of movement. Once the normal ultrasonocardiograph pattern of the mitral Starr-Edwards prosthesis is understood it may be possible to recognize abnormalities of valve function.

\section{Materials and methods}

The apparatus used in this study was the SmithKline Instrument Company's Eskoline 20 Diagnostic Ultrasonoscope; the specifications of this instrument have been previously described in an earlier paper from this department (Wharton, 1969). The transducer or ultrasound generating crystal is applied to the chest wall over the pros- 


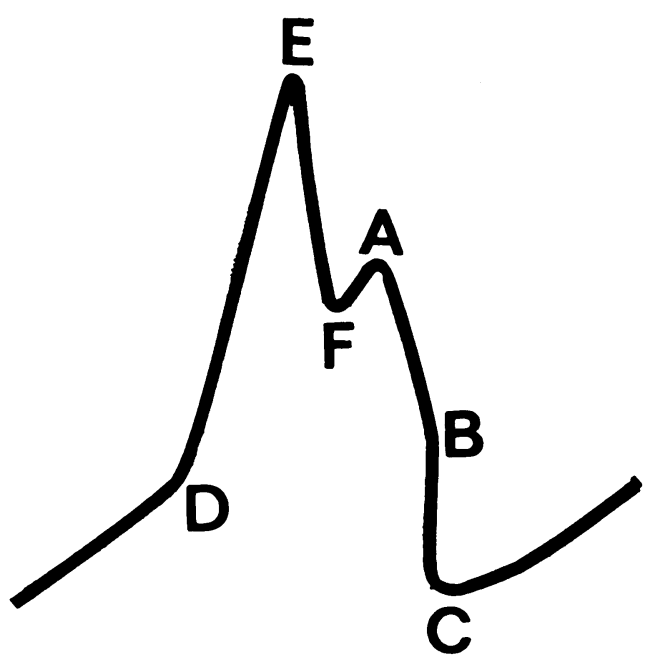

FIG. I The nomenclature of the ultrasonocardiograph of the mitral valve as proposed by Edler (I96I). Upward movement is opening of the valve and downward movement is closing. The ' $A$ ' deflection is in response to atrial contraction and is absent in atrial fibrillation.

thetic valve, the position of which can be located on the chest $x$-ray. The movement of the valve can be displayed on an oscilloscope either as a simple ' $A$ ' scan presentation which shows the echoes moving horizontally to and fro, or in the time-passage mode which shows the echoes moving, not only horizontally to and fro, but also vertically across the screen with respect to time giving a wave formation; this wave form can be photographed by the incorporated polaroid camera. The photograph produced in this way gives the displacement of the valve structures along the axis of the ultrasonic beam with respect to time. Alternatively, the wave form can be transferred to a multichannel recorder so that the movements of the valve can be recorded synchronously with electrocardiogram, phonocardiogram, and intracardiac pressure tracings. The present apparatus unfortunately allows only one ultrasonic echo to be selected on the multichannel recorder at one time, which means that cage and ball movements cannot be recorded together in this way. The polaroid photograph of the modified ' $A$ ' scan however allows multiple echoes to be recorded simultaneously.

A study was made of 16 patients with StarrEdwards prostheses in the mitral position (Table I). In 8 cases the modified ' $A$ ' scan only was used and in 8 cases the multichannel recorder was used; in the latter cases the ultrasonocardiogram was recorded not only in the sitting position but also in the supine and prone positions. Two patients underwent cardiac catheterization and the ball movement was recorded synchronously with left ventricular and pulmonary capillary venous pressures. A left ventricular cineangiogram was performed in three cases.

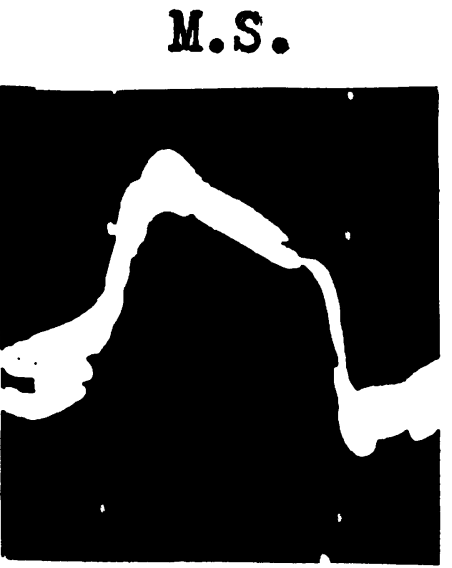

\section{STARR.}

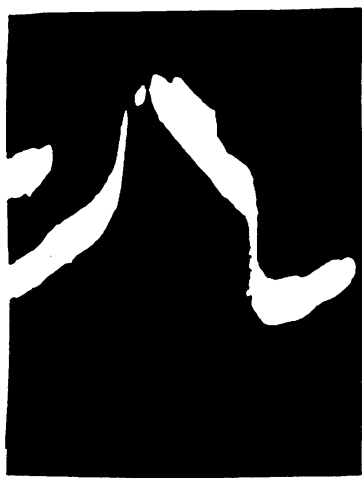

FIG. 2 Similarity between the ultrasonocardiograph of a patient with mitral stenosis (M.S.) and a patient with a normally functioning mitral Starr-Edwards prosthesis (Starr). Both patients have atrial fibrillation.

\section{Results}

Sixteen patients with mitral Starr-Edwards prostheses (Table I) were studied. The ultrasonocardiogram of the normally functioning mitral Starr-Edwards prosthesis is shown in Fig. 2 and compared with the ultrasonocardiogram of mitral stenosis. In the case of the prosthetic valve the ultrasonocardiogram is a recording of the ball movement. Fig. 3, however, shows that the movement is a composite picture of both the cage movement and the

\section{FIG. 3 Four echoes from a mitral Starr-}

Edwards prosthesis from the apex of the cage, the anterior and posterior surfaces of the ball, and the base of the cage.

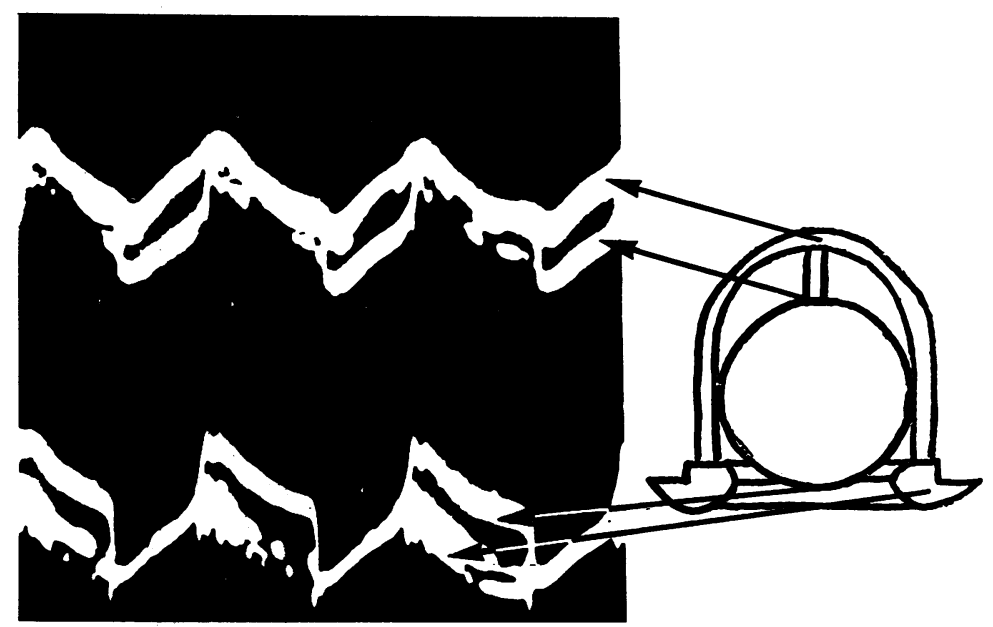




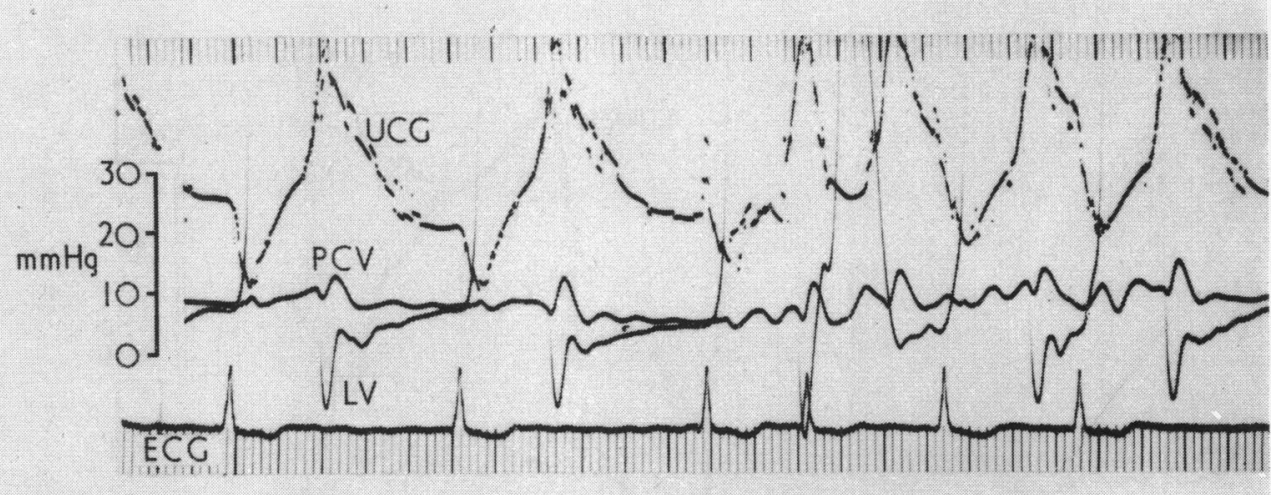

FIG. 4 Ultrasonocardiograph (UCG) with pulmonary capillary vein pressure (PCV), left ventricular pressure ( $L V)$, and electrocardiogram (ECG) recorded simultaneously. There is no significant pressure gradient across the prosthetic valve.

FIG. 5 The difference between the opening speed of the prosthetic mitral valve in the prone and supine positions in six patients. The filled-in circles represent a patient with a metal prosthetic ball, the remainder are silastic.

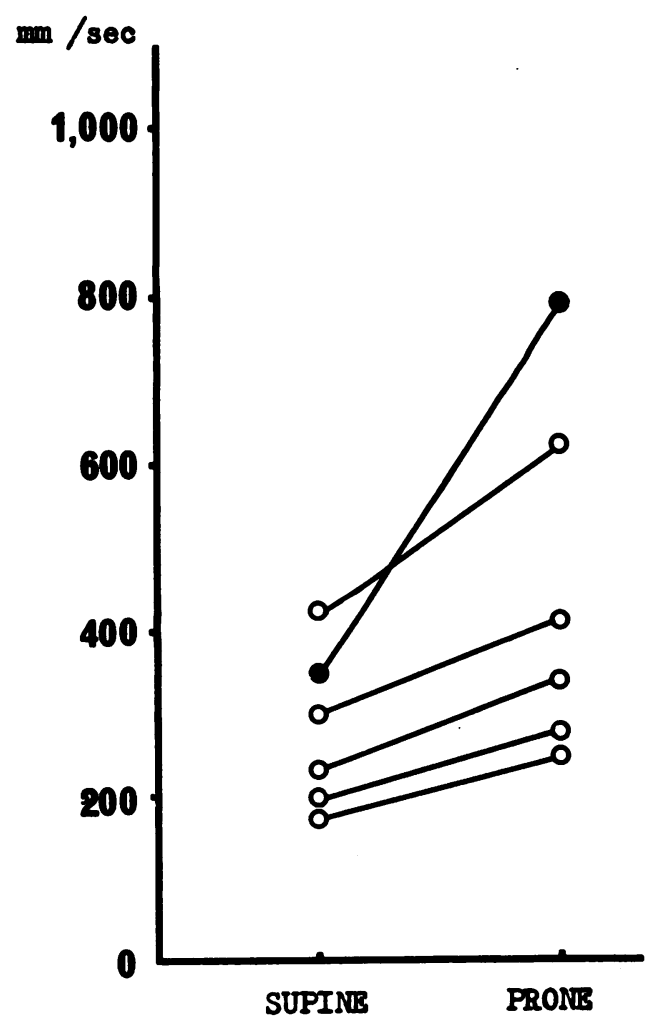

FIG. 6 Ultrasonocardiograph (UCG) recorded simultaneously with phonocardiograph and electrocardiograph (ECG). There are two opening sounds $(O S)$ as well as the first $(I)$ and second (2) heart sounds. These two opening sounds probably represent the 'bouncing' of the prosthetic ball as it strikes the apex of the cage in early diastole.
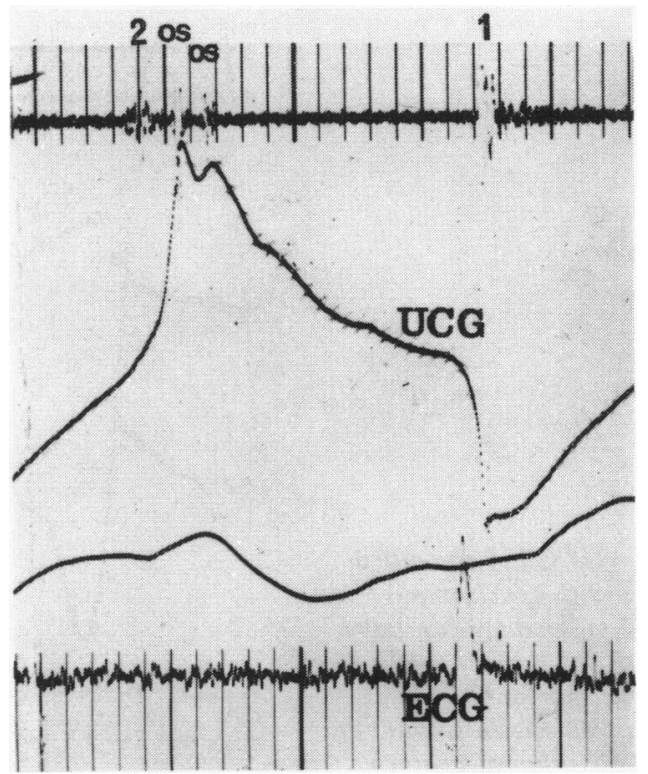

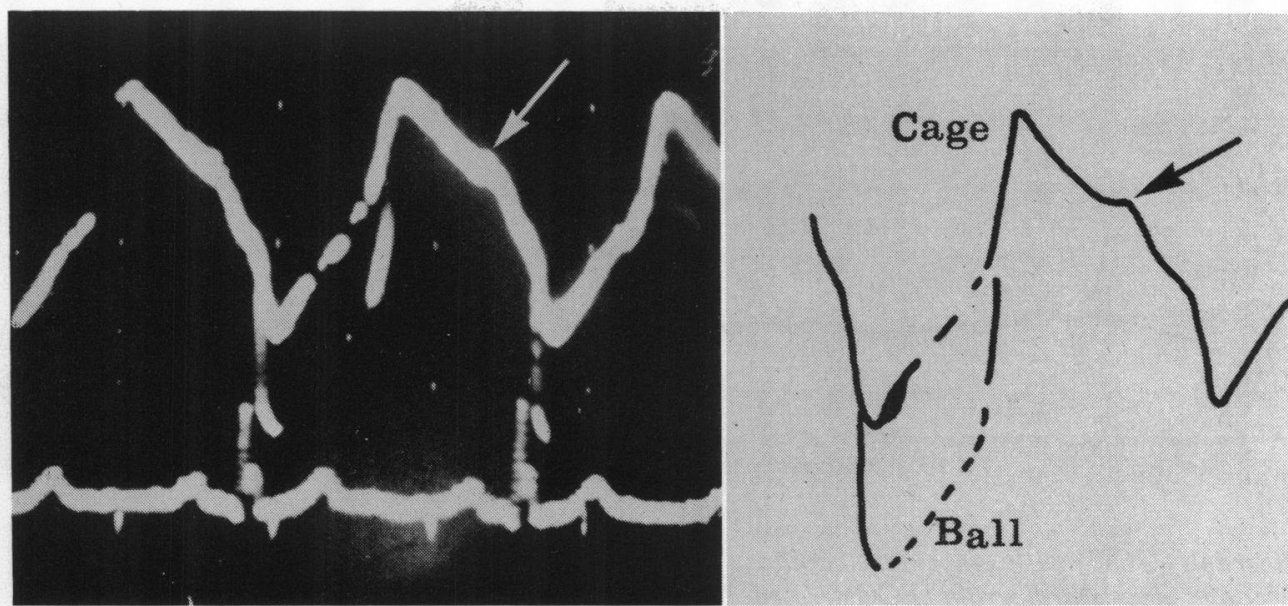

FIG. 7 The ' $A$ ' deflection (arrow) (see Fig. I) in a patient with a mitral Starr-Edwards prosthesis in sinus rhythm.

ball movement. The ball itself moves only to the open position, from D-E (Fig. I), and to the closed position from B-C (Fig. I). The remainder of the ultrasonocardiogram is formed by movement of the prosthetic cage, while the ball remains either against the apex or the valve ring. Fig. 4 shows the ultrasonocardiogram of a Starr-Edwards mitral prosthesis with synchronous left ventricular and pulmonary capillary venous pressures and the electrocardiogram; the pressures show that there is no significant pressure gradient across the prosthetic valve. The velocities recorded from the ultrasonocardiogram are seen in Table 2. The speed of opening of the ball is affected by gravity (Table 3 ). In the supine position the opening speed of the ball is reduced, especially in the one case (Case 16) with a metal ball (Fig. 5).

When the phonocardiogram is recorded simultaneously with the ultrasonocardiogram it can be seen (Fig. 6) that the opening sound
FIG. 8 Ultrasonograph (UCG) of the mitral Starr-Edwards prosthesis with synchronous left ventricular ( $L V)$ and pulmonary capillary vein (PCV) pressures with the patient in the prone position, showing the shorter ' $a$ ' to ' $c$ ' distance in the longer diastole due to sinking of the prosthetic ball in the direction of gravity.

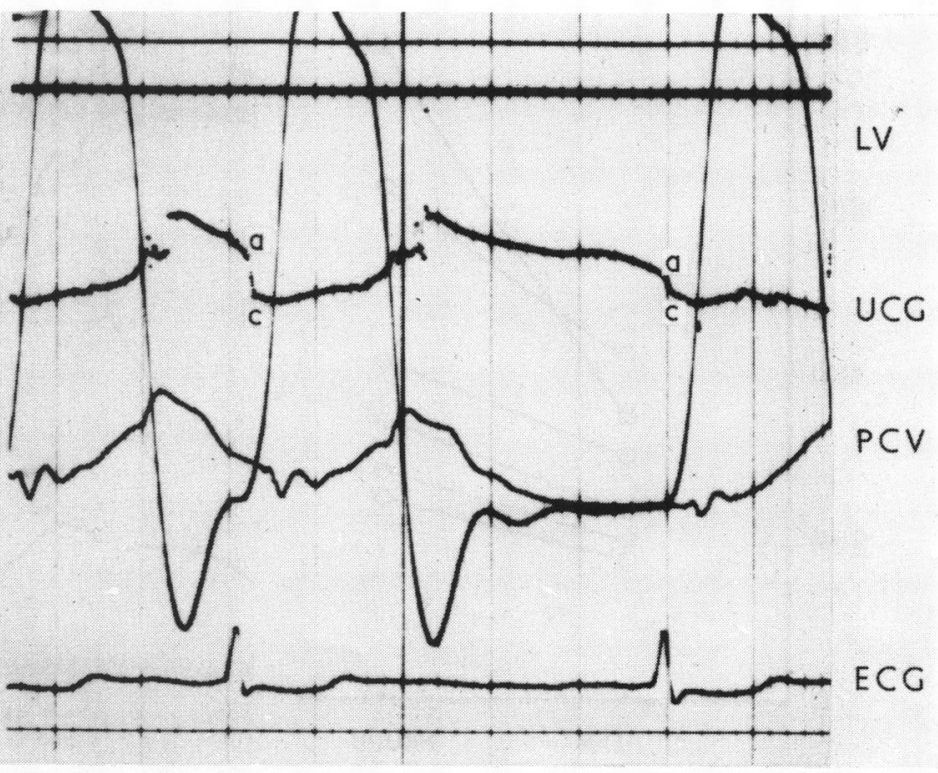



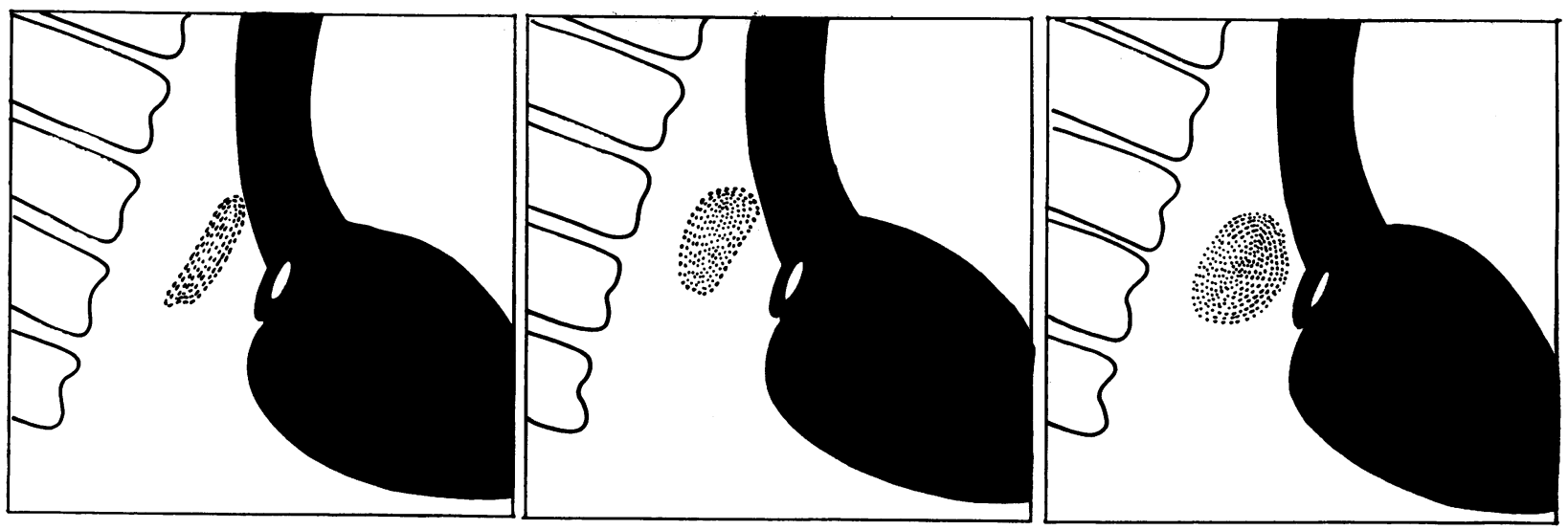

FIG. 9 Sketches taken from individual frames of a cineangiocardiogram in a patient with a normally functioning mitral Starr-Edwards prosthesis, showing a puff of contrast medium entering the left atrium at the onset of systole.

and the first sound occur at appropriate times. In some cases there is a double (Fig. 6) or even multiple opening sound; and in such a case the ball apparently 'bounces' at the apex of the cage. No significant difference in the $A_{2}$ - opening sound time between the small size (I and II) and large size (III and IV) Starr-Edwards prostheses is shown in this series.

Most of the patients in this series have atrial fibrillation, but in the presence of sinus rhythm the A wave of the ultrasonocardiogram is recorded (Fig. 7); this is movement of the cage, the ball remaining in the apex of the cage. When atrial fibrillation is present and a long diastole occurs (Fig. 8) the ball begins slowly to return to the base of the cage before the onset of systole, and the A-C distance is reduced.

Left ventricular cineangiograms were performed in three cases. The normally functioning valve (Fig. 9) produces a puff of incompetence at the onset of systole. The incompetent valve (Fig. Io) allows jets of regurgitation to pass the edge of the valve into the left atrium.

FIG. Io Sketches from individual frames of a cineangiocardiogram of a patient with a regurgitant mitral Starr-Edwards prosthesis showing regurgitant jets of contrast medium passing the edge of the valve into the left atrium.

$A$

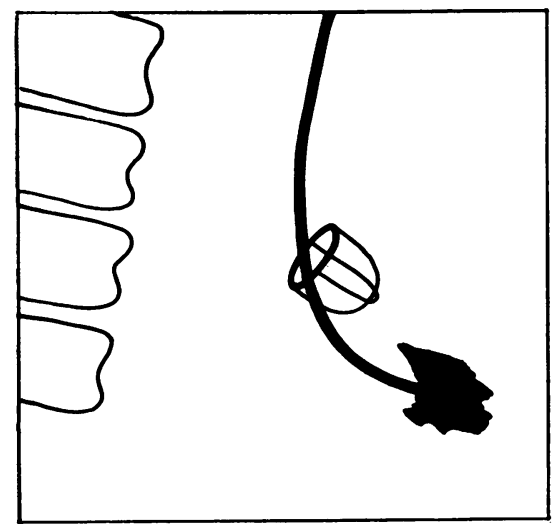

$B$

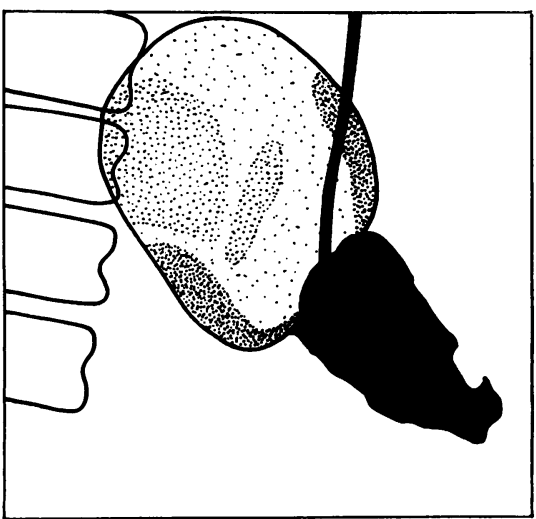

C

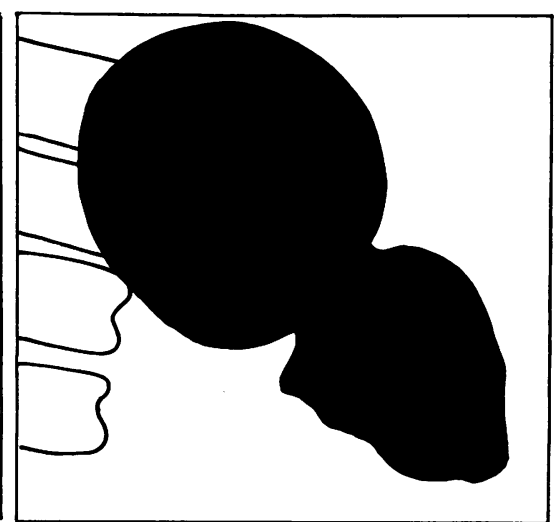




\section{Discussion}

The ultrasonocardiogram of the mitral StarrEdwards valve is different from the ultrasonocardiogram of the natural mitral valve.

In the natural valve the movement of the cusps is thought to be influenced by the existence of a vortex mechanism resulting from the central stream of blood flowing through the valve orifice (Reid, 1969). An eddy of blood is thought to flow round the ventricular side of the mitral cusps and to move them back towards each other as the central stream diminishes in diastole. This mechanism may explain the E-F movement of the anterior mitral cusp following the initial flow of blood from the left atrium into the left ventricle. Towards the end of diastole the left atrium injects blood into the left ventricle and a second opening and closing movement of the anterior cusp is seen (A-B); this brings the cusps towards the closed position before the onset of systole and no regurgitation occurs. In atrial fibrillation, however, mitral regurgitation towards the end of diastole may sometimes be shown by left ventricular cineangiography; this is possibly explained by the loss of late diastolic closure of the mitral valve in the absence of atrial contraction. Incompetence of a normal mitral valve can sometimes be seen during left ventricular cineangiography in the presence of ventricular ectopic beats.

A vortex mechanism as just described would not be expected to occur in the presence of a mitral Starr-Edwards prosthesis. No
TABLE I Patients with mitral Starr-Edwards prostheses

\begin{tabular}{|c|c|c|c|c|c|}
\hline $\begin{array}{l}\text { Case } \\
\text { No. }\end{array}$ & Sex & $\begin{array}{l}\text { Age } \\
(y r)\end{array}$ & $\begin{array}{l}\text { Valves } \\
\text { operated on }\end{array}$ & $\begin{array}{l}\text { Mitral } \\
\text { Starr size }\end{array}$ & Remarks \\
\hline $\mathbf{I}$ & $\mathbf{F}$ & 40 & $A+M$ & II & \\
\hline 2 & $\mathbf{F}$ & 52 & $\mathbf{M}$ & $\mathbf{I}$ & \\
\hline 3 & $\mathbf{F}$ & 55 & $\mathbf{A}+\mathbf{M}+\mathbf{T}$ & I & \\
\hline 4 & $\mathbf{F}$ & 42 & $\mathbf{A}+\mathbf{M}+\mathbf{T}$ & II & Haemolytic anaemia \\
\hline 5 & $\mathbf{F}$ & 29 & $M+T$ & II & Incompetent through suture line \\
\hline 6 & $\mathbf{F}$ & 47 & $\mathbf{M}+\mathbf{T}$ & II & \\
\hline 7 & $\mathbf{F}$ & $5 \mathbf{I}$ & $A+M$ & $I$ & \\
\hline 8 & $M$ & $3 I$ & $\mathbf{M}$ & IV & \\
\hline 9 & $\mathbf{F}$ & 39 & M & II & \\
\hline IO & $\mathbf{M}$ & 23 & $A+M$ & III & \\
\hline II & $\mathbf{M}$ & 35 & $\mathbf{M}+\mathbf{T}$ & II & \\
\hline 12 & $\mathbf{F}$ & 53 & $\mathbf{M}$ & II & Incompetent mitral Starr \\
\hline 13 & $M$ & 35 & $\mathbf{M}$ & IV & \\
\hline 14 & $\mathbf{M}$ & 42 & $\mathbf{M}$ & II & \\
\hline 15 & $\mathbf{M}$ & 23 & $\mathbf{M}$ & III & \\
\hline 16 & $\mathbf{F}$ & 34 & $\mathbf{M}$ & II & Metal prosthetic ball \\
\hline
\end{tabular}

Abbreviations: A, aortic; $M$, mitral; $T$, tricuspid

mechanism appears to exist which would encourage closure of the Starr-Edwards valve towards the end of diastole (except gravity during a long diastole in the supine subjects). Furthermore, we have shown, as have others (Glancy et al., 1969), that there is a small enddiastolic gradient across these prostheses in the mitral position, which would favour the valve remaining open until the onset of systole. The E-F slope of the ultrasonocardiogram of mitral Starr-Edwards prostheses reflects movement of the cage.

Metal and silastic prosthetic balls have a

TABLE 2 Velocities of ball and cage as recorded from ultrasonocardiograph

\begin{tabular}{|c|c|c|c|c|c|c|c|}
\hline $\begin{array}{l}\text { Case } \\
\text { No. }\end{array}$ & $\begin{array}{l}\text { Heart } \\
\text { rate/min }\end{array}$ & $\begin{array}{l}\text { Amplitude } \\
\text { of ball } \\
\text { movement } \\
(\mathrm{mm})\end{array}$ & $\begin{array}{l}\text { Amplitude } \\
\text { of cage } \\
\text { movement } \\
(\mathrm{mm})\end{array}$ & $\begin{array}{l}\begin{array}{l}\text { Cage } \\
\text { diastolic }\end{array} \\
(\mathrm{mm} / \mathrm{sec})\end{array}$ & $\begin{array}{l}\text { Cage } \\
\text { systolic } \\
(\mathrm{mm} / \mathrm{sec})\end{array}$ & $\begin{array}{l}\text { Ball } \\
\text { open } \\
(\mathrm{mm} / \mathrm{sec})\end{array}$ & $\begin{array}{l}\begin{array}{l}\text { Ball } \\
\text { close }\end{array} \\
(\mathrm{mm} / \mathrm{sec})\end{array}$ \\
\hline I & 60 & 23 & 15 & 25 & 55 & 160 & 325 \\
\hline 2 & 92 & $7 \cdot 7$ & 13.7 & 14.4 & 30 & 245 & 717 \\
\hline 3 & 80 & 5 & 13 & $17 \cdot 2$ & $8 \cdot 3$ & - & 123 \\
\hline 4 & 80 & $5 \cdot 2$ & $12 \cdot 2$ & 13.8 & $40 \cdot 6$ & 196 & 605 \\
\hline 5 & 100 & 10 & 21 & 23 & 31 & 369 & 736 \\
\hline 6 & 60 & 5.5 & 12.5 & 17 & 5.5 & 170 & 455 \\
\hline 7 & 80 & 9 & 17 & 28 & 20 & 208 & 623 \\
\hline 8 & 70 & $9 \cdot 3$ & $17 \cdot 3$ & - & 37 & 200 & - \\
\hline 9 & 60 & II & 14 & 37.5 & 44.5 & - & - \\
\hline I0 & 75 & 18 & - & $24 \cdot 6$ & 34 & 232 & 292 \\
\hline II & 90 & 14 & - & 26 & 32 & 310 & 645 \\
\hline 12 & 75 & 7 & I I & 21 & 19 & - & - \\
\hline 13 & 105 & 5 & 15 & 19 & - & 300 & 600 \\
\hline 14 & 70 & 7 & 14 & 23 & 18.5 & 208 & 510 \\
\hline 15 & 120 & 13.7 & 22 & 23 & 20 & 160 & 786 \\
\hline & 64 & II & 18 & 22 & 18 & 210 & 450 \\
\hline Mean & 80 & $9 \cdot 6$ & $16 \cdot 3$ & 25.4 & $29 \cdot 8$ & 225 & 557 \\
\hline
\end{tabular}


specific gravity slightly greater than blood, and we have shown (Fig. 5 and Table 3) that gravity affects the opening speed of the prosthetic valve, though this is unlikely to affect its function.

It is possible to record valve ring movement in normal and abnormal mitral valves, and this ring movement resembles the movement of the base of the mitral Starr-Edwards prostheses (Fig. II). The movement of the mitral cusp therefore also appears to be a composite picture of cusp and ring movement, in the same way that ball and cage movements make up the ultrasonocardiogram of the mitral Starr-Edwards prosthesis. Thus mitral valve anterior cusp movement may be analysed independently of ring movements (Fig. IIA). In more severe cases of mitral stenosis there appears to be little difference between the E-F slope and the E-F phase of the valve ring movement. This may result from a persistent diastolic gradient across the mitral valve. Severe cases of mitral stenosis may be shown to have only a small amplitude of movement of the anterior mitral cusp, and this amplitude of movement may, in extreme cases, be similar in extent to the amplitude of ring movement (Fig. I2). In such cases a separate echo of cusp movement is difficult to obtain. As might be expected from the pathological anatomy,

- the vortex mechanism does not appear to function in severe mitral stenosis.

The observations described suggest that the 'stenotic' E-F slope in the mitral StarrEdwards prosthesis results from the absence of movement of the prosthetic ball independently of the cage during that period, and that the same pattern is seen in severe stenosis of the natural mitral valve because of the

- absence, in this condition also, of independent movement of the cusp in relation to the valve ring.

4

\section{$\rightarrow$ References}

Edler, I. (196I). Atrioventricular valve motility in the living human heart recorded by ultrasound. Acta Medica Scandinavica, 170, Suppl. 370, p. 83.

- Edler, I., and Gustafson, A. (1957). Ultrasonic cardiogram in mitral stenosis. Acta Medica Scandinavica, 159, 85 .

Edler, I., Gustafson, A., Karlefors, T., and Christens-

son, B. (I96I). Mitral and aortic valve movements recorded by an ultra-sonic echo method. Acta Medica Scandinavica, Suppl. 370, p. 67.

I Edler, I., and Hertz, C. H. (1954). The use of ultrasonic reflectoscope for the continuous recording of the movements of heart walls. Kungliga Fysiografiska Sällskapets $i$ Lund Förhandlingar, 24, 40.

Effert, S. (1963). Diagnostic value of ultrasonic cardiography. British fournal of Radiology, 36, 302.

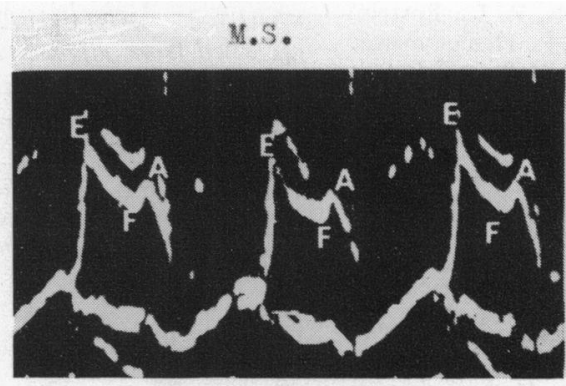

A

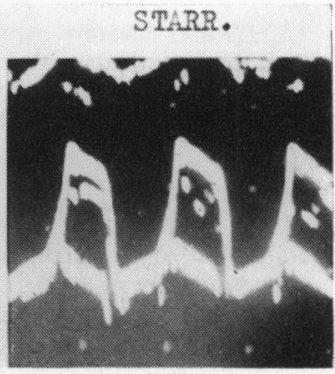

B
FIG. I I Ultrasonocardiograph recordings

from patients with (A) a moderately stenosed

mitral valve (M.S.) in sinus rhythm, and (B) a mitral Starr-Edwards prosthesis (Starr). In recording (A) from the stenosed mitral valve, a second echo can be seen below the cusp echo (resembling the echo from the prosthetic valve base in the second recording) which is probably from the mitral valve ring.

FIG. I2 Ultrasonocardiograph and electrocardiograph from a patient with severe mitral stenosis. The amplitude of excursion in this recording (10 $\mathrm{mm}$ ) is similar to the normal amplitude of excursion of the mitral valve ring.

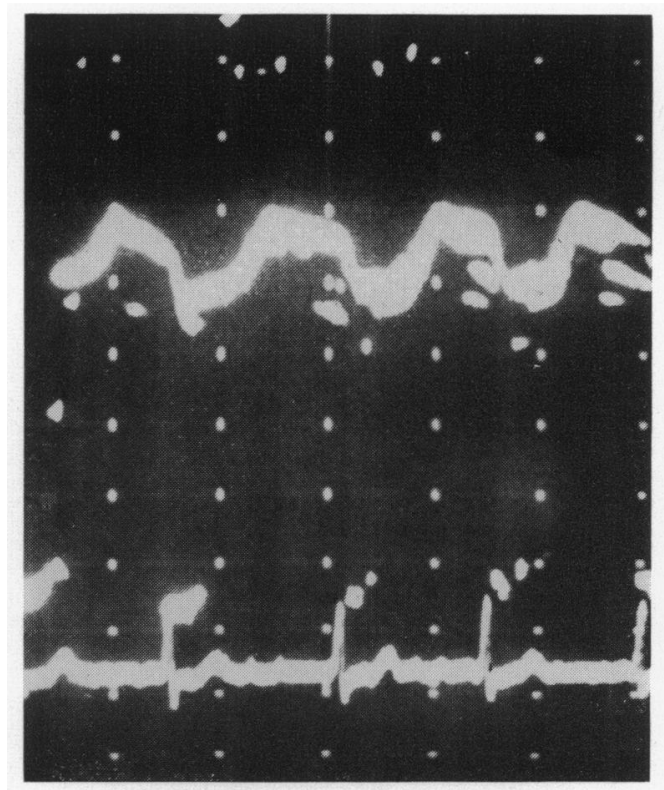


Glancy, L. D., O'Brien, K. P., Reis, R. L., Epstein, S. E., and Morrow, A. G. (1969). Hemodynamic studies in patients with $2 M$ and $3 M$ Starr-Edwards prostheses: Evidence of obstruction to left atrial emptying. Circulation, 39-40, Suppl. I, p. 113.

Joyner, C. R., Jr., Reid, J. M., and Bond, J. P. (1963). Reflected ultrasound in the assessment of mitral valve disease. Circulation, 27, 503.

Reid, K. (1969). Origin of the third heart sound. British Medical fournal, 4, 49.

Segal, B. L., Likoff, W., and Kingsley, B. (1966). Echocardiography; clinical application in mitral stenosis. Fournal of the American Medical Association, 195, 16I.

Segal, B. L., Likoff, W., and Kingsley, B. (1967). Echocardiography. Clinical application in combined mitral stenosis and mitral regurgitation. American fournal of Cardiology, 19, 42.

Wharton, C. P. F. (1969). Reflected ultrasound patterns in mitral valve disease. Guy's Hospital Reports, 118, 187.

Winters, W. L., Jr., Gimenez, J., and Soloff, L. A. (1967). Clinical application of ultrasound in the analysis of prosthetic ball valve function. American fournal of Cardiology, 19, 97.
TABLE 3 Velocities of ball and cage as recorded from ultrasonocardiograph in the supine and prone positions (Prone values above and supine values below)

\begin{tabular}{|c|c|c|c|c|c|c|}
\hline $\begin{array}{l}\text { Case } \\
\text { No }\end{array}$ & $\begin{array}{l}\text { Heart } \\
\text { rate/min }\end{array}$ & $\begin{array}{l}\text { Amplitude } \\
\text { of cage } \\
\text { movement } \\
(\mathrm{mm})\end{array}$ & $\begin{array}{l}\text { Cage } \\
\text { diastolic } \\
(\mathrm{mm} / \mathrm{sec})\end{array}$ & $\begin{array}{l}\text { Cage } \\
\text { systolic } \\
(\mathrm{mm} / \mathrm{sec})\end{array}$ & $\begin{array}{l}\text { Ball } \\
\text { open } \\
(\mathrm{mm} / \mathrm{sec})\end{array}$ & $\begin{array}{l}\begin{array}{l}\text { Ball } \\
\text { close }\end{array} \\
(\mathrm{mm} / \mathrm{sec})\end{array}$ \\
\hline 2 & $\begin{array}{r}100 \\
85\end{array}$ & $\begin{array}{l}15 \cdot 5 \\
16\end{array}$ & $\begin{array}{l}18 \\
19\end{array}$ & $\begin{array}{l}33 \\
30\end{array}$ & $\begin{array}{l}350 \\
430\end{array}$ & $\begin{array}{l}660 \\
680\end{array}$ \\
\hline \multirow[t]{2}{*}{6} & 60 & $12 \cdot 3$ & 14 & 14 & 96 & 312 \\
\hline & $\begin{array}{r}75 \\
100\end{array}$ & $\begin{array}{l}10 \cdot 8 \\
28\end{array}$ & $\begin{array}{l}13 \\
13\end{array}$ & $\begin{array}{l}8 \\
3 \cdot 8\end{array}$ & $\begin{array}{l}179 \\
415\end{array}$ & $\begin{array}{l}250 \\
500\end{array}$ \\
\hline 7 & 110 & 17 & 48 & $6 I$ & 300 & 950 \\
\hline \multirow[t]{2}{*}{13} & 120 & 16 & $2 \mathrm{I}$ & 36 & 625 & 693 \\
\hline & 100 & 13 & 32 & 25 & 425 & 1043 \\
\hline 14 & $\begin{array}{l}90 \\
80\end{array}$ & $\begin{array}{l}14.7 \\
16.4\end{array}$ & - & $\begin{array}{l}13.6 \\
18.8\end{array}$ & $\begin{array}{l}280 \\
198\end{array}$ & $\begin{array}{l}735 \\
690\end{array}$ \\
\hline $16^{\star}$ & 60 & 19 & 27 & 15 & 795 & 400 \\
\hline & 60 & 18 & 25 & 20 & 350 & 552 \\
\hline Mean & 88 & 24 & 31 & 20 & 524 & 666 \\
\hline
\end{tabular}

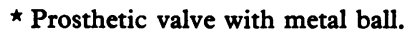

Advance Notice of Meeting

26-28 August 1971 International Cardiovascular Congress, Moscow. Details and application form on special travel arrangements through American Express from Miss North, or 7432030 Ext. 440. 